\title{
Ovular secretions as part of pollination mechanisms in conifers
}

\author{
Galatea Gelbart and Patrick von Aderkas* \\ Centre for Forest Biology, Department of Biology, University of Victoria, Victoria BC V8W 3N5, Canada
}

(Received 20 June 2001; accepted 3rd January 2002)

\begin{abstract}
Conifers have a diversity of pollination mechanisms that assist in the capture of pollen during pollination. Pollination mechanisms can be divided into a number of general types depending on whether they have an ovular secretion that interacts with the pollen. These types include mechanisms that never have a secretion, or those that have a delayed secretion, or the most common type in which a pollination drop is formed. This review outlines the evolutionary context of ovular secretions, describes the origins of these secretions within the ovule, their function in the two types of pollination mechanisms, and details the biochemical composition of these liquids. Not only do ovular secretions provide a germination medium for pollen, but they may also play a significant part in reducing pollen pollution by foreign species.
\end{abstract}

pollination mechanism / conifer / ovular secretion / pollination drop

Résumé - Les sécrétions ovulaires : leurs rôles dans les mécanismes de pollinisation des conifères. Les conifères possèdent divers mécanismes de pollinisation qui aident à la capture des grains de pollen lors de la pollinisation. Ces mécanismes peuvent être classés en quelques types généraux selon qu'une sécrétion ovulaire interagissant avec le pollen existe ou non. Ces différents types comprennent des mécanismes sans sécrétion, avec sécrétion retardée ou, et c'est le type le plus répandu, avec formation d'une goutte de pollinisation. Cet article décrit le contexte de ces secretions en terme d'évolution, leurs origines ovulaires, leurs fonctions dans les deux types de mécanismes de pollinisation, et leur composition biochimique. Les sécrétions ovulaires non seulement fournissent un milieu favorable à la germination du pollen, mais peuvent aussi diminuer de façon importante la pollution pollinique due à des pollens étrangers.

mécanisme de pollinisation / conifère / sécrétion / goutte de pollinisation

\section{INTRODUCTION}

The conifers are anemophilious; pollen is carried to the ovule by wind. Once pollen is blown in the proximity of the ovule entrance, it must be captured. Almost all of the capturing mechanisms known to date, which are collectively called pollination mechanisms, involve liquid secretions at some point during the process. For fertilization to occur, the pollen must be introduced into the ovule, it must germinate and penetrate both nucellus and archegonium before releasing its gametes into the egg. The simplicity of the route that pollen takes belies the complexity of the many pollen/ovule interactions.

* Correspondence and reprints

Tel.: 1250721 8925; fax: 1250721 7120; e-mail: pvonader@uvvm.uvic.ca 
One of the first interactions is between the pollen and an ovular secretion. Liquid secretion remains an incompletely explained phenomenon even today. There has been a general lack of explicit answers regarding its origins, function(s) and composition. It was Brown [4] who first distinguished gymnosperms from angiosperms. $\mathrm{He}$ noted that in angiosperms the ovules were enclosed in the pisitillate structure, but in gymnosperms the ovules were exposed. Gymnosperms lacked specialized receptive areas for the pollen, which had more direct access to the ovule than was found for angiosperms. Angiosperm ovules were located within ovaries, themselves buried within layers of complex floral structures. Angiosperm pollen traversed a variety of tissues before fertilization can occur. Superficially, it appeared that conifer gamete delivery was much less complicated because of the exposed nature of the ovule. In 1841, Vaucher [73] published his lengthy four-volume treatise, "Histoire Physiologique des Plantes d'Europe" in which he was the first to record the presence of a pollination drop exuded from the micropyle of gymnosperms. Strasburger [61] also stated that pollination drops, such as those he described from Juniperus, Taxus, and Thuja, were a feature that all gymnosperms shared.

The purpose of this review is fivefold: (1) to outline the evolutionary context of ovular secretions, (2) to describe the origins of these secretions within the ovule, (3) to describe the role of such liquids in the diverse types of pollination mechanisms found in conifers today, (4) to describe their biochemical composition, and finally, (5) to discuss their role in barriers to breeding.

\section{EVOLUTION OF OVULAR SECRETIONS}

The early seed ferns, the pteridosperms, had a pollination drop and non-saccate pollen. Later, the first gymnosperms, of which Lebachia is an example of the primitive condition, had erect ovules, a pollination drop and saccate pollen [15]. In the upper Permian, an inverted ovule and pollen grain with lateral sacci appeared for the first time. These air sacs were generally thought to be for upward flotation toward the inverted ovule's micropyle; these are seen in Albania and Pseudovoltzia [15]. Fossilized saccate pollen is also known in Cordaitales, Callistophytaceae, early Coniferales, Caytoniales, Podocarpus and Pinaceae. The only fossil evidence for drops is from Callospermarion pusillum, (a seed fern from the Pennsylvanian), which has a droplet with pollen embedded in it [47]. This droplet has also been viewed as a sealing mechanism for the micropyle, since it appeared to be resinous. The presence of saccate pollen grains in pteridosperms has been interpreted by Taylor and Millay [67] to be an indication of anemophilous pollination during the Carboniferous. Because saccate pollen are generally associated with ovular secretions, it is likely that the widespread presence of saccate pollen is indicative of the widespread occurrence of pollination drops during this period.

Ovular secretions are also known from angiosperms. The secretions do not mediate pollen transfer between the outside of the plant and the ovule, but generally function within the confines of the ovary where they play a role in directing pollen growth [56]. Franssen-Verheijen and Willemse [19] showed that secretions of strictly ovular origin are found. They may also play a role in incompatibility mechanisms functioning at the level of the ovule [51]. Given that droplets are found not only in early vascular plants, but in the most highly evolved angiosperms, we can conclude that ovular secretions are the rule rather than the exception in reproductive systems of seed plants.

Placing the ovular secretions of conifers in an evolutionary context depends a great deal upon the phylogeny selected. Conifer evolutionary phylogenies can be divided into precladistic and cladistic views. Precladistic morphologists have variously interpreted the relationships amongst the conifers based on structural features [46], in particular cone structure [6], or fossil evidence [18]. The conifers have been divided into as few as six and as many as nine families including Araucariaceae, Cephalotaxaceae, Cupressaceae, Phyllocladaceae, Pinaceae, Podocarpaceae, Sciadopityaceae, Taxaceae, and Taxodiaceae. With the exception of Phyllocladaceae, all families have been studied using molecular markers, with the result that the fairly comprehensive molecular systematic study has been completed. A cladistic analysis using molecular markers for 28S rRNA genes based on Stefanovic et al. [59] was used to produce the evolutionary series shown in table I. Such analysis has reinforced the validity of Sciadopityaceae, but cast doubt on the Taxodiaceae, which were lumped together in a large expanded Cupressaceae. With the development of molecular markers, a number of conifer phylogenies have been published [5, 21, 25, 59].

In modern conifers, ovular secretions are widespread (table I). Pollination drops are also known from groups considered more basal to the conifers, such as cycads and ginkgos. Of the basal conifer clades, members of the Pinaceae generally have ovular secretions with the 
Table I. Types of ovular secretion found in gymnosperm species listed in ascending order of evolution according to the cladistic analysis of Stefanovic et al. (1998).

\begin{tabular}{lll}
\hline Species & family & type of ovular secretion \\
\hline Cycas revoluta & Cycadaceae & pollination drop \\
Ginkgo biloba & Ginkgoaceae & pollination drop \\
Pinus nigra & Pinaceae & pollination drop \\
Abies grandis & Pinaceae & no drop \\
Tsuga heterophylla & Pinaceae & no drop \\
Pseudotsuga menziesii & Pinaceae & post-pollination pre-fertilization drop \\
Podocarpus macrophyllus & Podocarpaceae & pollination drop \\
Araucaria araucana & Araucariaceae & no drop \\
Sciadopitys verticillata & Sciadopityaceae & pollination drop \\
Taxus baccata & Taxaceae & pollination drop \\
Cephalotaxus harringtonia & Cephalotaxaceae & pollination drop \\
Taxodium distichum & Cupressaceae (s.l.) & pollination drop \\
Juniperus communis & Cupressaceae (s.s.) & pollination drop \\
\hline
\end{tabular}

notable exception of Abies and some species in Tsuga. The ephemeral nature of secretions had prevented their observation in early phenological studies of some genera. The pinaceaous genera in which droplets have now been found within the last half century include Cedrus [63], Pseudotsuga [3] and Larix [2]. Pollination drops are known from Phyllocladaceae, Podocarpaceae (with the exception of Saxegothaea), Taxaceae, Sciadopityaceae and Cupressaceae. Araucariaceae is the only family that never has pollination drops.

Ovular secretions are part of a complex of phenomena associated with fertilization. In more primitive plants, such as seed ferns, liquids in the ovule provided a medium in which flagellated sperm could access the egg. Initially, integuments were heavily vascularized. Consequently, the original ovular secretions may have had a more direct connection with the vascular system, similar to guttation drops. With greater evolutionary advancement, there was a steady decline in vascularization of integuments from seed ferns to cycads and ginkgos; until in conifers, ovules are not vascularized [22]. There was also evolution in the structures that deliver male gametes. Originally, male gametophytes, or pollen, had pollen tubes that delivered flagellated sperm into specialized pollen chambers, as is still the case in Ginkgo and cycads. Later in evolution, the sperm lost their flagellae and the gametes were delivered directly into the egg by the pollen tube, as is currently found in conifers. This represents the culmination of the switch from a zooidagamous method of male gamete delivery typical of lower plants to siphonogamy, typical of all higher seed plants. The pollen tube enhances the efficiency of fertilization, eliminating the losses inherent with sperm release in water outside the gametophyte. Nevertheless, liquid secreted by the ovule is still required during prefertilization events in gymnosperms, even in completely siphonagamous groups such as the ginkgos and conifers.

Ovular secretions may not be the ancestral condition. According to Owens et al. [43], early conifers may not have had ovular exudates, but, instead, depended on rainfall for pollen delivery into the micropyle of the ovule. Under this scenario, rain water, and any saccate pollen grains found in the liquid, were drawn into ovules. The scavenging of liquids by ovules was due to the capillary structure of the ovule. Pollen scavenging ovules are considered the primitive condition [48]. In our view, this theory neither considers the widespread occurrence of ovular secretions, nor does it account for the evolutionary evidence of such liquids in all living representatives of more basal clades, and, notably, in families found in xeric climates. The primitive condition must be a pollination mechanism with an ovular secretion. 


\section{ORIGINS OF THE OVULAR SECRETION}

The ovule secretes the liquid from its internal tissues via the micropyle. The nucellus is most frequently considered the origin, but other sources, such as the integument and megagametophyte have also been suggested. From an evolutionary perspective, both Chamberlain [9] and Dogra [14] mentioned a nucellar origin of drops in the Cycadales.

In 1911, Tison [68] photographed pollen of Cupressus funebris floating in a pollination drop. He proposed that the drop was a nucellar secretion of symplastic origin. Experiments with stains showed continuity between drop and nucellus, as breakdown products of the nucellus were transferred to the pollination drop. Degeneration of the nucellus varies among genera. Tissue breakdown is quite extensive in some genera, such as Cephalotaxus [10], Cupressus [68], and Podocarpus [71]. In others, breakdown is restricted to the uppermost layer, as has been shown in studies of Sequoiadendron [64] and Phyllocladus [68]. Finally, a number of genera including Cedrus [63], Taxus [1], Larix [42], Pseudotsuga [66] produce drops but show no degeneration of the nucellus.

The secretion mechanism is not known, but various interpretations have been put forward. Strasburger [61] favored a micropylar origin. McWilliam [30] not only concluded that the nucellus of Pinus was the probable origin of the drop, but that the mechanism was a type of guttation. By contrast, Ziegler [79] suggested that only in conditions of high humidity could drops be produced in Taxus. He proposed that the drops formed because of atmospheric absorption of water by the high concentration of chemicals on the surface of the nucellus. Metabolic inhibitors did not prevent formation, leading him to conclude that the drop was produced apoplastically.

Fujii [20] suggested that secretion from Taxus ovules originated apoplastically from the nucellus. There is debate about how this apoplastic origin of the drop can function, as Seridi-Benkaddour and Chesnoy [55] point out that the gymnosperm ovule is unvascularized, and does not have conducting cells. In short, there is no continuity between the vascular system and the drop. Furthermore, the drop composition is not similar to guttation fluids. This has been confirmed by Carafa et al. [8], who mention that the nucellus, even before it breaks down, does not appear to have much anatomically in common with secretory tissues.

Little evidence is available for drop origin from tissues other than the nucellus. There is some electron microscopic evidence in Larix occidentalis that a secretion from the micropyle occurs immediately following engulfment that causes the pollen to hydrate and swell [42]. Takaso and Owens [63] have concluded, from their interpretation of micrographs, that the drop in Cedrus is nucellar in origin. In contrast, a gametophytic origin has been postulated for the drops in Pinus [54] and Pseudotsuga [64]. In all of these cases, the source of drops has been inferred but not proven. No immunolocalization studies have been published.

We know very little about the control of pollination drop secretion and resorption in non-coniferous species. In other gymnosperms, such as Welwitschia, secretion is related to nucellar breakdown, and resorption is due to evaporation [8]. Doyle and O'Leary [16] were to the first to prove that active resorption occurred in gymnosperms. When Pinus pollen landed on a pollination drop, it induced the withdrawal of that drop within about half an hour. A neighboring unpollinated ovule did not show active resorption of the drop. However, such behaviour is not universal in conifers, and secretion and resorption is quite variable within different genera, let alone between families. In Picea, droplets are repeatedly secreted, facilitating a sort of pollen scavenging [48]. Podocarpus secretes new drops even after pollen capture, whereas Phyllocladus produces drops only before pollen capture. Once the pollen lands, secretion ends [72].

In conifers in which the drops are reabsorbed following contact with pollen, there is neither an identified resorption mechanism, nor is there a tissue that can be shown to store the reabsorbed drop. Resorption occurs after secretion has stopped, and consequently these two processes must be regulated in a coordinated manner. How chemical signals or products of gene regulation mediate this system is unknown. The lack of continuity between the vascular system and the ovule implies that the phenomenon is regulated by the water relations of the ovule, as separate from the general water relations of the tree. This requires much further work.

The timing of pollination drops is aimed to coincide with anthesis [54]. Generally, production of gametes in conifers has evolved to occur during a season of abundant moisture. High relative humidity is thought to be essential for pollination drop formation in a Taxus [79]. Low relative humidity causes pollination drops to evaporate quickly. But there are limits to the advantages of high relative humidity. Since rain will cause premature germination of pollen many ovulate cones have waxy surfaces to prevent entry and subsequent accumulation of rainfall or dew [54]. In Taxus, rainfall is even thought to be disruptive to pollination as it washes away the pollination drops and diminishes fertilization success [68]. 


\section{POLLINATION MECHANISMS}

Historically, reviews of pollination mechanisms have largely focused on the morphological aspects $[15,36,43$, 57, 72]. Inevitably, the classification of pollination mechanisms has changed as more of these are discovered and described. As Tomlinson pointed out "We are a long way from a complete understanding of the mechanisms of pollen capture in conifers, but it is clear that they are very diverse..." [72].

Pollination mechanisms can be divided between those that have ovular secretions and those that do not (table II). The list of those without ovular drops has been shrinking as closer inspection reveals secretions of short duration that had been overlooked in previous studies. The remaining types of pollination mechanisms have secretions that coincide with pollination and are known as pollination drops. Depending on the genus, ovules can be quite fixed in their orientation. As a consequence, micropyles and their drops are rigidly oriented. Pollen that lands in drops that are facing downwards must be drawn into the micropyle. Saccate pollen float and are drawn in by the receding meniscus of the drop [70]. Many genera have ovules that are randomly oriented. Saccate pollen can be drawn in as previously described, or non-saccate pollen can fall directly into the drop, sinking into the micropyle until they contact the nucellus. Pollination drop retraction can occur passively, because of evaporation, or actively, by as yet undescribed mechanisms. Recently, Tomlinson et al. [72] used resorption as a criterion in the schematic separation of various pollination mechanisms. Unfortunately, much of what has been concluded in the literature is based on observation and not on controlled experimentation. This aspect needs much more controlled work before general conclusions can be drawn. Given the number of genera once thought to not have a drop that are now recognized to possess one, it would seem that the onus should be to prove that the remaining genera do not have a drop. Careful scrutiny may reveal short-lived, delayed or confined drops.

The list of pollination mechanisms itemized in table II and illustrated in figure 1 will be discussed in more detail below, with particular emphasis on the ovular secretions.

\subsection{No ovular secretion}

Although the absence of an ovular secretion is a unifying feature in this group, each genus has a different mechanism with which to capture pollen.

In Tsuga pattoniana, the ovule has an asymmetric stigmatic flare and a deep slit on the one side of the micropylar canal. Saccate pollen is received on the stigmatic flare, which then reflexes over the pollen. The nucellar tissue continues to grow until it almost reaches the micropylar opening, and the pollen germinates. A pollen tube grows toward the raised nucellus tissue [15]. In Tsuga heterophylla, pollen received anywhere on the scales of the female cone germinates where it lands [34]. The high humidity in the cones stimulates germination. The pollen tubes grow toward the micropyle from quite long distances. Modifications associated with pollen capture include pollen spines that stick to the highly textured surface of the bract of the cone [13]. How pollen tubes are able to find the ovular opening is not understood and has not been studied in an experimental manner.

In Abies, the ovule has a long, wide micropylar canal that bends over the base of the ovuliferous scale so that the micropyle points away from the cone axis. A long delay takes place between pollination and growth of the pollen tube [15]. The canal tip is flared into a funnelshaped stigmatic surface. Pollen catches on the stigmatic flaps, on tiny droplets that are secreted on the funnel tip,

Table II. Pollination mechanisms in conifers ordered by type of ovular secretion.

1. No secretion: Araucariaceae, some species of Tsuga, Abies.

2. Delayed secretion: liquid appears many weeks after pollination. It is confined to the micropylar canal: Larix, Pseudotsuga. Sometimes called a post-pollination prefertilization drop.

3. Pollination drop - secretion timed to coincide with pollination.

(i) Only saccate pollen accepted - ovules inverted: Pinus, Picea, Cedrus.

(ii) Only saccate pollen accepted - ovules upright: Picea orientalis.

(iii) Only saccate pollen accepted - ovules haphazardly oriented: some Podocarpaceae (Podocarpus).

(iv) Non-saccate pollen: Cupressaceae, Sciadopityaceae, Taxaceae, Taxodiaceae some Podocarpaceae (Phyllocladus). 


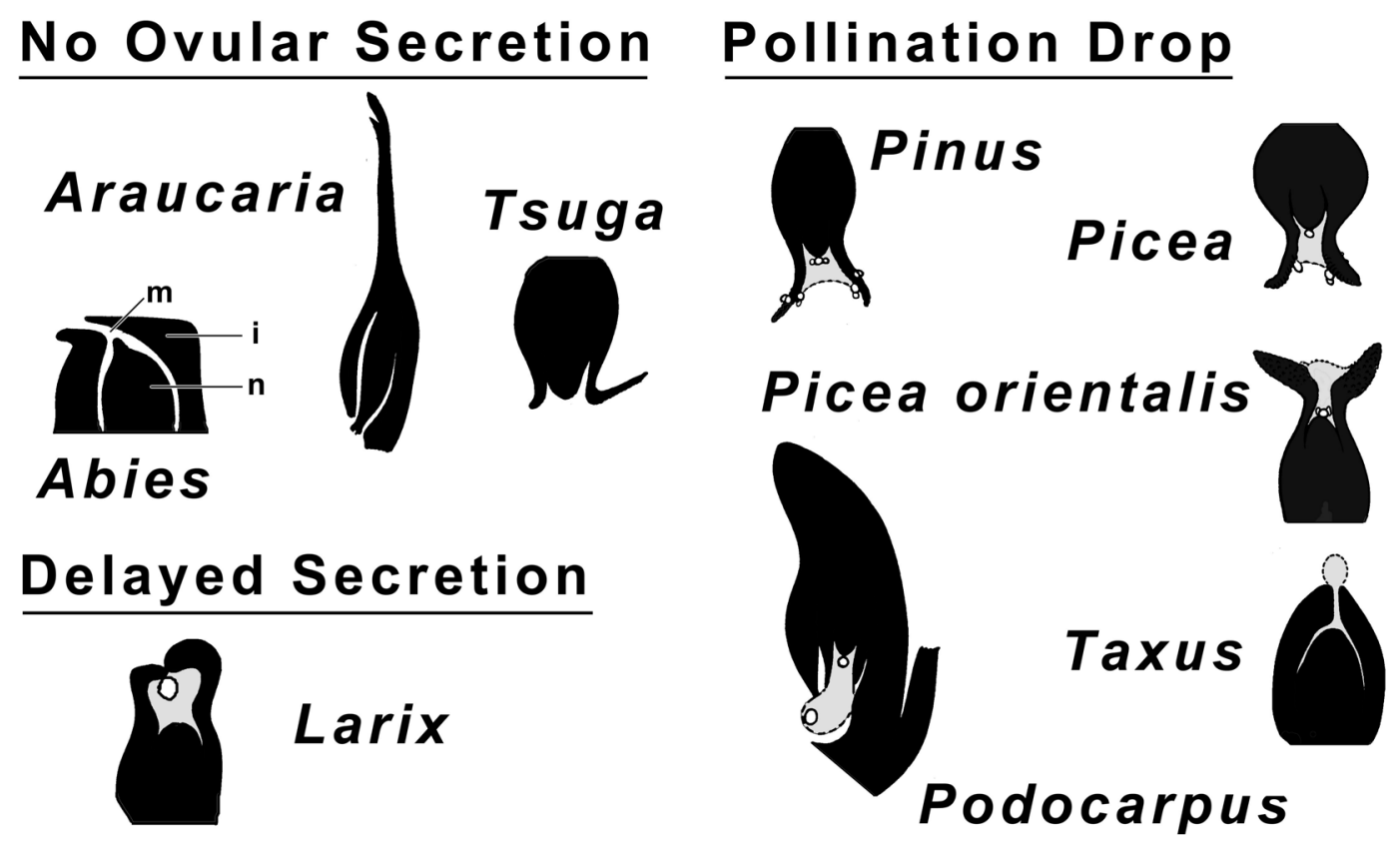

Figure 1. Schematic diagrams of ovules in cross-section of different representative genera. Characteristic conifer ovule parts, including the micropyle (m), integument (i) and nucellus (n), are indicated for Abies. Ovular silhouettes modifed from those published in Doyle [15].

which then folds inward, carrying pollen to the nucellus, which, during the course of development, has continued to grow, filling the micropyle [58]. These small secretions originate from the micropyle. Without any compositional analysis, it is hard to know how much similarity they share with ovular secretions of other genera. The fact that such drops may play a role in pollen adhesion, implies that they are functionally quite different. In Araucaria and Agathis, the nucellus grows beyond the ovule's opening, allowing pollen grains to germinate on nucellar tissue directly.

\subsection{Delayed secretions}

In Pseudotsuga and Larix, the micropylar canal is short with an asymmetric tip. There is a large stigmatic flap on the adaxial, upper side, and a smaller one on the lower side. In Pseudotsuga, thick, hair-like projections are present on the stigmatic area. Non-saccate pollen lands on the flap, which then collapses inward over the pollen $[15,57]$. The two flaps of the micropyle continue to grow, gradually enclosing the pollen grains. These elongate in the micropylar canal $[3,39]$. There is a long delay of many weeks between pollen capture and pollen germination [12]. In Larix pollen is captured in a generally similar fashion to events described above for Pseudotsuga. However, the effective period of receptivity was considered by Villar et al. [74] to be only a day long, which is much shorter than what has been found from controlled crosses.

A post-pollination prefertilization drop fills the micropylar canal 5-7 weeks after pollination [53, 64, 75]. Pollen is carried to the inverted ovules by the liquid and germinates on the nucellus. Based on micrograph interpretation, as many as three waves of post-pollination drops are thought to be secreted in Pseudotsuga [62]. However, freezing the ovules in liquid nitrogen on the tree branch and dissecting the ovules at subzero temperatures showed that there was only one short period during which a drop appeared within the micropyle of Larix and Pseudotsuga [75, 76]. These drops are very small, ranging in average size from $18-28 \mu \mathrm{m}$, depending on the ovule size, which can vary between trees [75]. 


\subsection{Pollination drop}

\subsubsection{Only saccate pollen accepted - ovules inverted}

For all members of Pinus, Cedrus and Picea (except Picea orientalis), the female cone is erect at pollination. The ovules, located on the bracts, are horizontally positioned, but because the micropylar tube bends over the base of the ovuliferous scale, the opening of the micropyle points downward. Two opposing extensions of the integument, or micropylar arms, exude small sticky droplets to which pollen adhere [16, 35] like in Abies. However, a drop fills the micropylar canal, expands between the arms that have gathered the pollen, and then withdraws into the ovule, bringing the pollen to the pollen chamber at the tip of the nucellus. Pollen floats on the meniscus because of the air bladders, or sacci. In Pinus, the presence of pollen in the drop initiates a faster withdrawal than if the pollination drop was free of pollen according to Doyle and O'Leary [16], but Lill and Sweet [29] working in the same genus were unable to repeat this result. Owens and Blake [35] suggested that a nectarylike tissue located at the tip of the nucellus is responsible for secretion of the drop. Sarvas [54] stated that the origin of the liquid was in the tissue below the nucellus, noting that the liquid merely passed through the nucellus on its way in and out of the micropyle. In Picea glauca, ovules within a female cone exude drops asynchronously over the course of one week. The drops appear sequentially in an acropetal manner within the cone [35]. In Cedrus, it was recently found that there are microdrops on the apical part of the integument, followed by an ephemeral drop that had been previously overlooked. This drop brings the pollen into the micropyle [63].

\subsubsection{Only saccate pollen accepted - ovules upright}

In Picea orientalis, ovules are horizontally oriented. The micropylar tube is bent over the base of the ovuliferous scale. This is similar to the pollination drops discussed above, but because the cone is inverted, the opening of the ovule and the pollinaton drop face upwards. Saccate pollen is received on stigmatic flaps at the tip of the tube. A copious pollination drop gathers the pollen from these flaps. The sacci of pollen are unusual as they provide no buoyancy, but absorb the liquid, wetting the pollen and allowing it to sink into the drop [15, 50]. Pollen presence causes active drop resorption.

\subsubsection{Only saccate pollen accepted - ovules haphazardly oriented}

In some Podocarpaceae, a large drop is secreted. The saccate pollen floats in the drop, allowing it to orient the germinal furrow towards the nucellus. The fluid is reabsorbed due to evaporation. Large numbers of pollen are drawn into the ovule by pollen scavenging $[69,72]$.

\subsubsection{Non-saccate pollen accepted}

Pollination drops are produced from ovules of haphazard orientation. The non-saccate pollen sinks into the drop, which is resorbed. This is the most common pollination mechanism found in conifers. It is known from all advanced families including Cupressaceae (s.l.), Sciadopityaceae, and Taxaceae. Ovules are flaskshaped with a narrow short neck out of which a pollination drop is exuded, possibly secreted by the nucellus $[37,38]$. Drops are exuded from some of the ovules asynchronously, for a few days to a week. Non-saccate pollen sinks in the pollination drop and swells [15]. The exine ruptures, and germination takes place. The fluid volume decreases due to evaporation, and the pollen is reabsorbed into the ovule. There is some speculation that some of these genera may possess a more active mechanism. Following pollination, the micropyle seals as cells that line the canal elongate to form a micropylar collar [38]. A possible role for secretory compounds is to help seal the micropyle, as has been suggested for seed ferns [67].

An historical list of genera in which pollen-induced withdrawal of secretions has been observed by a variety of researchers, has recently been published [72]. Given the general paucity of information and in the absence of any identified mechanisms, it is difficult to conclude much about either the general or specific nature of this phenomenon. Tomlinson et al. [72] reported that Phyllocladus ovules produced a drop that receives pollen directly. The drop recedes completely after pollen lands. Secretion then stops, implying a metabolic change in the tissues responsible for secretion.

\section{CONSTITUENTS OF THE DROP}

Early studies indicated drops were composed of a variety of relatively simple water-soluble compounds. The first report of chemical composition of pollination drops showed a number of compounds in Taxus including 
glucose, calcium and amino acids [20]. The main constituents found in Cupressus funebris were similar: glucose, calcium and malic acid [68]. Generally, studies since these early efforts have focused on carbohydrates, amino acids and a miscellany of other compounds. No reports of the osmotic potential of the drop have been published.

Carbohydrate studies can be divided into two groups; those that report sucrose and its breakdown products, glucose and fructose, and studies that report complex polymers and their breakdown products, i.e. uronic acid.

Sucrose is the preferred compound for carbon transfer in conifers. Developing ovules act as sinks for sucrose, but when the pollination drop is found, all studies find that sucrose is not the dominant sugar. In Pinus nigra, the pollination drop had a $1.25 \%$ total concentration of Dglucose, D-fructose, and sucrose in the drop [30]. Fructose was the highest concentration (at $40 \mathrm{mM}$ ), followed by glucose $(33 \mathrm{mM})$ and sucrose $(2.5 \mathrm{mM})$. In vitro experimentation with Pinus mugo pollen indicated that during germination pollen takes up fructose preferentially over other sugars [32]. In Cephalotaxus drupacea, fructose was found to be $77 \%$ of the total sugar in the drop [55]. They also found glucose (2.4\%), and an unidentified sugar X $(5.0 \%)$. The pollination drop of Picea engelmannii was found to have a higher concentration of glucose $(4.3 \%)$ than fructose $(3.8 \%)$ [40]. No sucrose was found. Fructose was noted to be the predominant also in the drops of Thuja orientalis and Taxus baccata [55].

Carbohydrates other than hexose sugars have been found in drops. The concentration varies from species to species. In a study of pollination drops of Cephalotaxus drupacea, Seridi-Benkaddour and Chesnoy [55] found mixed polymers ( $15 \%$ of total drop), galactose (57\% of the polymer concentration), arabinose (18\%), rhamnose $(8 \%)$ and mannose $(4 \%)$. Uronic acids, which are released after extensive breakdown of the nucellus (characteristic of this species) were present at $23 \%$. In Thuja, the main sugars in the drop, after fructose, were mixed polymers $(65 \%)$, and two unidentified sugars: $\mathrm{X}(12 \%)$ and $\mathrm{Y}$ (22\%). Uronic acids were present at 14\% [10]. In Taxus, the sugar concentrations found were mixed polymers $(38 \%)$, sucrose (30\%), and unidentified sugar Y $(29 \%)$. The uronic acid concentration in Taxus was high (44\%) [10].

Ziegler [79] also found many amino acids, peptides, inorganic phosphate, malic acid and citric acid in Ephedra and Taxus. He noted that the content of the drop is similar to that of extracts of nucellar cells. In Cephalotaxus drupacea, five amino acids were isolated - proline, asparagine, glutamate, alanine and serine [55]. The amino acids found in Thuja were: serine, glycine, alanine and glutamate in descending order of concentration [10]. The amino acids present in Taxus were glutamate, proline, alanine, glutamine and asparagine. Duhoux and Pham Thi [17] found that Juniperus communis pollen tubes have improved growth in vitro when the same major amino acids as those found in ovules were added to the medium. Biochemical composition of the drop may play a role in optimizing selection of appropriate pollen, but this has not been studied further.

Unpublished work from the Ph.D. thesis of Said [52] indicates that proteins are abundant in the ovular secretion of Larix decidua. As proteins have numerous roles in reproduction in angiosperms, it would be surprising if they did not also play significant role in regulating a number of aspects of reproduction in gymnosperms. Villar et al. [74] have shown that esterases secreted from the micropylar arms of Japanese larch may interact with pollen trapped by the papillae.

Until recently, a limitation to analysis was the small volume of ovular secretions, which led to a bottleneck in compound identification. However, even this limit is no longer as formidable as it once was given recent advances in tandem mass spectrometry [26] provide reliable methods for identifying low quantities of compounds found in the drop.

\section{BREEDING BARRIERS AND OVULAR SECRETIONS: FACTS AND THOUGHTS}

Seed yield is affected by losses during reproduction. In conifers, these losses occur either prezygotically or post-zygotically [77]. Most are thought to be the latter [78]. Prezygotic losses occur at any point during development when male or female gametophytes are lost. Lowering the number of effective gametes available directly affects seed yield. Pollen loss may be due to meiotic irregularities, failure in the timing of pollen dispersion, or in the loss of viability. Female losses occur when either cones, ovules, megagametophytes or eggs abort. These may also be due to meiotic irregularities, developmental abnormalities, or in response to biotic factors, such as failure of pollen to stimulate cone development, or abiotic factors such as temperature. Male losses can be more complex when they involve an interaction with the ovule, such as might occur with the pollination drop or its equivalent. These interactions that 
occur prior to fertilization can be of a general nature or of a specific nature.

On a general level, the ovular secretion provides a medium for pollen capture and pollen germination. The drop is an aqueous solution in which the pollen can germinate. On the other hand, the ability of pollination drops to pull in pollen grains to the nucellus is similar in nature to the general function of microdroplets found on micropylar arms of some species [65]. These drops allow adhesion of pollen, but not in a specific manner. The droplets may represent a very broad form of recognition, but no experiments have been carried out to date to show that this adhesion has any specificity, nor has any biochemical analysis been carried out to confirm the composition of these droplets. This should be investigated in more detail.

The pollen tube of the appropriate species develops in this aqueous solution and then penetrates the plant. The pollen therefore interacts with a secretion of the ovule, then with the tissues of the ovule itself. This interaction may influence male competition and/or selection.

If the ovular secretion does play a role in mate selection, it only does so at a particular level of selection. If pollen of the maternal tree is unable to self-fertilize, then this would be indicative of self-incompatibility mechanisms. If pollen of one genotype is unable to compete against pollen of another genotype, then this would be evidence for male competition. Finally, if ovules are able to exclude foreign pollen from its eggs, then a barrier to gamete pollution may exist.

Most of the detailed studies of self-incompatibility, whether in Pinus [23], Pseudotsuga [33], or Thuja [41] have not discussed secretions and their effect on early pollen growth, as selfed crosses generally failed only after fertilization. Other studies claim that prezygotic selfincompatibility mechanisms are in the nucellus [27] and in the archegonium [49]. Some evidence for secretion-related self-incompatibility comes from two studies. In Pseudotsuga menziesii plasmolysis of pollen in self-pollinated ovules was observed [66]. In Larix decidua [28], it was noted that pollen inside ovules in self-crosses often failed to reach the nucellus. No mechanisms were suggested.

There have been no designed studies of male competition within the micropyle between different genotypes, whether of the same species or different species. Some observations of pollen behaviour have been made from sectioned material. Takaso and co-workers [66] noted that not all pollen grains in a Douglas fir micropyle were equally vigorous. Some had plasmolyzed and died, implying a selection during the long period between pollination and fertilization. Interspecific hybridization studies of Pinus suggest that in wide crosses pollen germination is reduced [31] and pollen tube growth is diminished $[7,60]$. Most of this effect was ascribed to the lack of complementarity in chemical composition between nucellus and pollen [31], but some of the complementarity may have already been determined by the interaction between pollen and pollination drop. In Pinus, wide crosses are inviable, aborting after fertilization and possibly demonstrating incompatibility of pollen in the nucellus [24].

In nature, pollen of one species will enter the ovule of other species, even if entirely unrelated. Although there are pollination mechanisms that preferentially select for saccate pollen over non-saccate pollen, there is no evidence that a given pollination mechanism can distinguish between different kinds of saccate pollen, with the exception of Picea orientalis [50]. Equally, there is no evidence that non-saccate pollination mechanisms are able to select between species. As a result, pollen of different species may be introduced into the micropyle. As Tomlinson and co-workers [72] have recently shown, many different species of pollen could be collected by pollination drops of the podocarps that they tested.

When foreign pollen encounters the ovular secretion, selection may occur. A possibility that we are currently investigating in our laboratory is that ovular secretion represents a direct method of female selection that is based on the different composition of secretions from one genus to the other in their concentrations of sugars, amino acids, and other substances. Pollen of one genus that pollutes the ovules of another will likely face a different osmotic environment, differing not only in composition but perhaps in osmotic potential. This may lead to an environment that may favor the growth of one species of pollen over that of another. This could be described as a "home advantage" and represents a form of mate selection. If we further consider that pollination drops may have phenological complexities in their secretion and resorption, as well as in their interactions with pollen, then the picture begins to become more complicated.

A molecular basis for any interactions cannot yet be provided as analysis of these drops and of the pollen coat compounds that might be reasonable candidates for such interactions is yet in its infancy. No molecular biological investigation of gene expression have been undertaken with prefertilization ovular tissues of conifers.

Another method of female selection in gymnosperms is to delay fertilization, presumably to increase mate 
choice. Ovular secretions are very important in regulating such events. In cycads and in many conifers in which pollination drops mediate germination, pollen not only germinate readily, but fertilize the eggs within days. In pines, pollen germinates almost immediately in the pollination drop, but it may take many months from pollination before fertilization occurs. Pollen tube growth is arrested by processes within the nucellus. Pettitt [45] points out that the evolutionary trend has been toward faster germination. By comparison, angiosperms may germinate in a matter of minutes. The delay in conifers is manifest in different ways. In Larix [75] and Pseudotsuga [76], pollination occurs, but many weeks elapse before a drop appears and germination occurs. In all of the above cases, it is not known whether resumption of growth is due to signals of a broad physiological nature or whether there is a nucellus/pollen interaction mediated by compounds such as proteins or hormonal signals.

If pre-zygotic selection is occurring, then there may be gene products present in the ovular tissue that interact with pollen. Pettitt [44] remarked that conifer pollen is able to germinate in the ovules of the unrelated Gingko, but that after the pollen tubes penetrate the nucellus, they became disoriented and grew away from the ovules. Takaso and Owens [62] suggested that two types of ovular secretions may exist in Pseudotsuga; one that triggers pollen tube growth and another that is inhibitory and may select against unhealthy or less vigorous pollen. Pettitt [44] found evidence in Cycas that glycoproteins are involved in pollen-ovule interactions. Both the pellicle on the stigma and the pollen were coated with concanavalin A binding sites. These binding sites as well as the presence of lectins on the stigma could be involved in the inhibition of incompatible pollen germination. Cell surface glyco-molecules are also important for cell-cell recognition, particularly in the growth of pollen tubes since synthesis of cell material is required [11].

Superficially, no female selection is suspected at any level in genera in which interspecific hybridization is common, such as Larix, which could be considered a species complex, rather than 13 or 14 well-defined, reproductively isolated species. However, for selection on one pollen species over another to occur, there need not be an absolute barrier to reproduction, but merely a stochastic advantage. In short, it need only be shown that the pollen of Larix decidua may germinate more readily and have an advantage over pollen of any or all other species in the same genus. It would be enough to provide evidence that Larix decidua, for example, possessed a subtle barrier. Such a study would require extensive dissection, microscopy and seed yield evaluation of polymix pollinated females.

In addition to acting as a germination medium, and a selective factor in reducing foreign pollen competition, the pollination drop is a liquid rich in sugars and amino acids, in which every fungus and bacterium ought to thrive. Sarvas [54] noted that the mechanical function of the pollination drop of Pinus was so undiscriminating that any airborne particles, including insect eggs, could be pulled back inside ovule. This was particularly true near roadways, where there was much greater air movement. Our experience in dissecting thousands of ovules of Larix, Pseudotsuga, Pinus and Picea indicates that bacteria and fungi do not thrive. The micropyle and nucellus of most ovules are very clean and can be cultured directly without any sterilization. The pollination drop, it would appear, is probably able to eliminate unwanted organisms that naturally occur. The mechanism is currently unknown, but most certainly warrants closer investigation. It does raise the possibility that an ancestral function of the pollination drop may have been to act as a defense barrier. The correct pollen is able to overcome the defenses of the gymnosperm to penetrate to the egg.

\section{CONCLUSION}

The ovular secretions of conifers have evolved from similar secretions that occur in more basal clades. Their chemical composition differs from genus to genus, and probably between species. Droplets are produced within the complex of events that characterize pollination mechanisms. These have been described for many genera, but more research is required into the ovular secretion's influence on mate selection before a comprehensive understanding of reproduction in conifers is achieved. Conifers show elements of prezygotic selection that may overcome the effects of pollen pollution.

Acknowledgments: The authors would like to thank Stephen O'Leary and Marlies Rise for their helpful comments and Dr. Nicole Dumont-Béboux for her help with the translation. This work was supported by a grant from the Natural Sciences and Engineering Research Council of Canada to PvA. 


\section{REFERENCES}

[1] Anderson E.D., Owens J.N., Megagametophyte development, fertilization, and cytoplasmic inheritance in Taxus brevifolia, Int. J. Plant Sci. 160 (1999) 459-469.

[2] Barner H., Christiansen H., The formation of pollen, the pollination mechanism, and the determination of the most favourable time for controlled pollinations in Larix, Silvae Genet. 9 (1960) 1-11.

[3] Barner H., Christiansen H., The formation of pollen, the pollination mechanism, and the determination of the most favourable time for controlled pollination in Pseudotsuga menziesii, Silvae Genet. (1962) 89-102.

[4] Brown R., Character and description of Kingia, a new genus of plants found on the southwest coast of New Holland: with observations on the structure of its unimpregnated ovulum; and on the female flower of Cycadeae and Coniferae, in: King P.P. (Ed.) Narrative of a Survey of the Intertropical and western coasts of Australia, performed between years 1818 and 1822, John Murray, London, 1827, pp. 534-565.

[5] Brunsfeld S.J., Soltis P.S., Soltis D.S., Gadek P.A., Quinn C.J., Strenge D.D., Ranker T.A., Phylogenetic relationships among the genera of Taxodiaceae and Curpressaceae: evidence from $r b c$ L sequences, Syst. Bot. 19 (1994) 253-262.

[6] Buchholz J.T., The classification of the Coniferales, Trans. Ill. Acad. Sci. 25 (1934) 112-113.

[7] Buchholz J.T., The cause of sterility in cross-pollinations between species of pines, Amer. J. Bot. 31 supplement (1944) 2.

[8] Carafa A.M., Carratu G., Pizzolongo P., Anatomical observations on the nucellar apex of Welwitschia mirabilis and the chemical composition of the micropylar drop, Sex. Plant Repro. 5 (1992) 275-279.

[9] Chamberlain C.J., Gymnosperms: structure and evolution, Dover Publications Inc., New York, 1935.

[10] Chesnoy L., Les sécrétions dans la pollinisation des gymnospermes, Acta bot. Gall. 140 (1993) 145-156.

[11] Cheung A.Y., The pollen tube growth pathway: its molecular and biochemical contributions and responses to pollination, Sex. Plant Repro. 9 (1996) 330-336.

[12] Christiansen H., On the pollen grain and the fertilization mechanism of Pseudotsuga menziesii (Mirbel) Franco var. viridis Schwer., Silvae Genet. 18 (1969) 97-104.

[13] Colangeli A.M., Owens J.N., Postdormancy seed-cone development and the pollination mechanism in western hemlock (Tsuga heterophylla), Can. J. For. Res. 19 (1989) 44-53.

[14] Dogra P.D., Pollination mechanisms in gymnosperms, in: Advances in palynology, Annual report, National Botanical Garden, Lucknow, 1964.

[15] Doyle J., Development lines in pollination mechanisms in the Coniferales, 24 (1945) 43-62.

[16] Doyle J., O'Leary M., Pollination in Pinus, Sci. Proc. R. Dublin Soc. 21 (1935) 180-190.
[17] Duhoux E., PhamThi A., Influence de quelques acides aminés libres de l'ovule sur la croissance et le développement cellulaire in vitro du tube pollinique chez Juniperus communis (Cupressacées), Physiol. Plant. 50 (1980) 6-10.

[18] Florin R., Evolution in cordaites and conifers, Acta Horti Berg. 15 (1951) 1-389.

[19] Franssen-Verheijen A.A.W., Willemse M.T.M., Micropylar exudate in Gasteria (Aloaceae) and its possible function in pollen tube growth, Amer. J. Bot. 80 (1993) 253-262.

[20] Fujii K., Uber die Bestäubungstropfen der Gymnospermen, Ber. Dtsch. Bot. Ges. 21 (1903) 211-217.

[21] Gadek P.A., Alpers D.L., Heslewood M.M., Quinn C.J., Relationships within Cupressaceae sensu lato: A combined morphological and molecular approach, Amer. J. Bot. 87 (2000) 1044-1057.

[22] Gifford E.M., Foster A.S., Morphology and evolution of vascular plants, 3rd ed., W.H. Freeman and Co., San Francisco, 1989.

[23] Greenwood M.S., Gene exchange in loblolly pine: the relation between pollination mechanism, female receptivity and pollen availability, Amer. J. Bot. 73 (1986) 1443-1451.

[24] Hagman M., Incompatibility in forest trees, Roy. Proc. Soc. London (B) (1975) 313-326.

[25] Hart J.A., A cladistic analysis of conifers: preliminary results, J. Arn. Arb. 68 (1987) 269-307.

[26] Kinter M., Sherman N.E., Protein sequencing and identification using tandem mass spectrometry, John Wiley and Sons, New York, 2000.

[27] Kormutak A., Self-incompatibility in silver fir (Abies alba), Biologia 54 (1999) 101-105.

[28] Kosinski G., Megagametogenesis, fertilization, and embryo development in Larix decidua, Can. J. For. Res. 16 (1986) 1301-1309.

[29] Lill B.S., Sweet G.B., Pollination in Pinus radiata, New Zeal. J. For. Sci. 7 (1977) 21-34.

[30] McWilliam J.R., The role of the micropyle in the pollination of Pinus, Bot. Gaz. 120 (1958) 109-117.

[31] McWilliam J.R., Interspecific incompatibility in Pinus, Amer. J. Bot. 46 (1959) 425-433.

[32] Nygaard P., Utilization of exogenous carbohydrates for tube growth and starch synthesis in Pine pollen suspension cultures, Physiol. Plant. 39 (1977) 206-210.

[33] Orr-Ewing A.L., Further inbreeding studies with Douglas fir, For. Chron. 33 (1957) 18-32.

[34] Owens J.N., Blake M.D., Pollen morphology and development of the pollination mechanisms in Tsuga heterophylla and T. mertensiana, Can. J. Bot. 61 (1983) 3041-3048.

[35] Owens J.N., Blake M.D., The pollination mechanism of Sitka spruce (Picea sitchensis), Can. J. Bot. 62 (1984) $1136-1148$

[36] Owens J.N., Blake M.D., Forest tree seed production: a review of the literature and recommendations for future research, Canadian Forestry Service, Agriculture Canada, 1985. 
[37] Owens J.N., Molder M., Pollination, female gametophyte, and embryo and seed development in yellow cedar (Chamaecyparis nootkatensis), Can. J. Bot. 53 (1975) 186-199.

[38] Owens J.N., Molder M., Sexual reproduction in western red cedar (Thuja plicata), Can. J. Bot. 58 (1980) 1376-1393.

[39] Owens J.N., Morris S.J., Cytological basis for cytoplasmic inheritance in Pseudotsuga menziesii. I. Pollen tube and archegonial development, Amer. J. Bot. 77 (1990) 433-445.

[40] Owens J.N., Simpson S.J., Caron G.E., The pollination mechanism of Engelmann spruce (Picea engelmannii), Can. J. Bot. 65 (1987) 1439-1450.

[41] Owens J.N., Colangeli A., Morris S.J., The effect of self-, cross-, and no pollination on ovule, embryo, seed, and cone development in western red cedar (Thuja plicata), Can. J. For. Res. 20 (1990) 66-75.

[42] Owens J.N., Morris S.J., Catalano G.L., How the pollination mechanism and prezygotic and postzygotic events affect seed production in Larix occidentalis, Can. J. For. Res. 24 (1994) 917-927.

[43] Owens J.N., Takaso T., Runions C.J., Pollination in conifers, Trends Plant Sci. 3 (1998) 479-485.

[44] Pettitt J.M., Detection in primitive gymnosperms of proteins and glycoproteins of possible significance in reproduction, Nature 266 (1977) 530-532.

[45] Pettitt J.M., Ultrastructural and immunocytochemical demonstration of gametophytic proteins in the pollen tube wall of the primitive gymnosperm, Cycas, J. Cell Sci. 57 (1982) 189-213.

[46] Pilger R., Coniferae, in: Engler A., Prantl K. (Eds.), Die Natürlichen Planzenfamilien 13 (1926) 121-149.

[47] Rothwell G., Evidence for a pollination-drop mechanism in Paleozoic pteridosperms, Science 198 (1977) 1251-1252.

[48] Runions C.J., Owens J.N., Pollen scavenging and rain involvement in the pollination mechanism of interior spruce, Can. J. Bot. 74 (1996) 115-124.

[49] Runions C.J., Owens J.N., Evidence of pre-zygotic selfincompatibility in a conifer, in: Owens S.J., Rudall P.J. (Eds.), Reproductive biology, Royal Botanic Gardens, Kew, 1998, pp. 255-264.

[50] Runions C.J., Rensing K.H., Takaso T., Owens J.N., Pollination of Picea orientalis (Pinaceae): saccus morphology governs pollen buoyancy, Amer. J. Bot. 86 (1999) 190-197.

[51] Sage T.L., Bertin R.I., Williams E.G., Ovarian and other late-acting self-incompatibility systems, in: Williams E.G., Knox R.B., Clarke A.E. (Eds.), Genetic control of self-incompatibility and reproductive development in flowering plants, Kluwer Academic Publishers, The Netherlands, 1994, pp. 116-140.

[52] Said C., Différenciation et reconnaissance des gamétophytes male et femelle chez Larix leptolepis : étude structurale, Ph.D. thesis, Université Claude Bernard - Lyon I, 1988.

[53] Said C., Villar M., Zandonella P., Ovule receptivity and pollen viability in japanese larch (Larix leptolepis Gord.), Silvae Genet. 40 (1991) 1-6.
[54] Sarvas R., Investigations on the flowering and seed crop of Pinus sylvestris, Metsämtutkimuslaitoksen Julkaisuja (Comm. Inst. For. Fenn.) 53(4) (1962) 1-198.

[55] Seridi-Benkaddour R., Chesnoy L., Secretion and composition of the pollination drop in the Cephalotaxus drupacea (Gymnosperm, Cephalotaxaceae), in: Cresti M., Gori P., Pacini E. (Eds.), Sexual reproduction in higher plants, Springer Verlag, Berlin, 1988, pp. 345-350.

[56] Shimizu K., Okada K., Attractive and repulsive interactions between female and male gametophytes in Arabidopsis pollen tube guidance, Development 127 (2000) 4511-4518.

[57] Singh H., Embryology of gymnosperms, Gebrüder Borntraeger, Stuttgart, 1978.

[58] Singh H., Owens J.N., Sexual reproduction in subalpine fir (Abies lasiocarpa), Can. J. Bot. 59 (1981) 2650-2666.

[59] Stefanovic S., Jager M., Deutsch J., Broutin J., Masselot M., Phylogenetic relationships of conifers inferred from partial 28S rRNA gene sequences, Amer. J. Bot. 85 (1998) 688-697.

[60] Stockwell W.P., Pre-embryonic selection in the pines, Jour. Forest. 37 (1939) 541-543.

[61] Strasburger E., Die Bestäubung der Gymnospermen, Jena. Z. Med. Naturw. 6 (1871) 249-262.

[62] Takaso T., Owens J.N., Effects of ovular secretions on pollen in Pseudotsuga menziesii (Pinaceae), Amer. J. Bot. 81 (1994) 504-513.

[63] Takaso T., Owens J.N., Pollination drop and microdrop secretions in Cedrus, Int. J. Plant Sci. 156 (1995) 640-649.

[64] Takaso T., Owens J.N., Postpollination-prezygotic ovular secretions into the -micropylar canal in Pseudotsuga menziesii (Pinaceae), J. Plant Res. 109 (1996) 147-160.

[65] Takaso T., Owens J.N., Ovulate cone, pollination drop, and pollen capture in Sequoiadendron (Taxodiaceae), Amer. J. Bot. 83 (1996) 1175-1180.

[66] Takaso T., von Aderkas P., Owens J.N., Prefertilization events in ovules of Pseudotsuga: ovular secretion and its influence on pollen tubes, Can. J. Bot. 74 (1996) 1214-1219.

[67] Taylor T.N., Millay M.A., Pollination biology and reproduction in early seed plants, Rev. Palaeobot. Palynol. 27 (1979) 329-355.

[68] Tison A., Remarques sur les goutelettes collectrices des ovules des Conifères, Mem. Soc. Linné Normandie 24 (1911) $51-61$.

[69] Tomlinson P.B., Pollen scavenging as a novel reproductive mechanism in Podocarpaceae, Res. Expl. 7 (1991) 188-195.

[70] Tomlinson P.B., Functional morphology of saccate pollen in conifers with special reference to Podocarpaceae, Int. J. Plant Sci. 155 (1994) 699-715.

[71] Tomlinson P.B., Braggins J.E., Rattenbury J.A., Pollination drop in relation to cone morphology in Podocarpaceae: a novel reproductive mechanism, Amer. J. Bot. 78 (1991) 1289-1303. 
[72] Tomlinson P.B., Braggins J.E., Rattenbury J.A., Contrasted pollen capture mechanisms in Phyllocladaceae and certain Podocarpaceae (Coniferales), Amer. J. Bot. 84 (1997) 214-223.

[73] Vaucher J.P., Histoire physiologique des plantes d'Europe, Vol. 4, Marc Aurel Frères, Paris, 1841.

[74] Villar M., Knox R.B., Dumas C., Effective pollination period and nature of pollen-collecting apparatus in the gymnosperm, Larix leptolepis, Ann. Bot. 53 (1984) 279-284.

[75] von Aderkas P., Leary C., Ovular secretions in the micropylar canal of larches (Larix kaempferi and L. x eurolepis), Can. J. Bot. 77 (1999) 531-536.
[76] von Aderkas P., Leary C., Micropylar exudates in Douglas fir - timing and volume of production, Sex. Plant Repro. 11 (1999) 354-356.

[77] Willson M.F., Sexual selection in plants: perspective and overview, Amer. Nat. 144 (1994) S13-S39.

[78] Willson M.F., Burley N., Mate choice in plants: tactics, mechanisms and consequences, Princeton University Press, Princeton, 1983.

[79] Ziegler H., Ueber die Zusammensetzung des "Bestäubungstropfens" und den Mechanismus seiner Sekretion, Planta 52 (1959) 587-599.

To access this journal online: www.edpsciences.org 